\title{
SPATIAL VARIABILITY ANALYSIS OF SOIL PROPERTIES WITHIN A FIELD
}

\author{
Gang Liu ${ }^{1}$, Xuehong Yang ${ }^{2}$ \\ ${ }^{1}$ Key Laboratory of Modern Precision Agriculture System Integration, Ministry of Education, \\ China Agricultural University, Beijing, Beijing, China, 10008, Tel: 86-10-62736741, \\ Email:pac@cau.edu.cn \\ ${ }^{2}$ China Agricultural University, Beijing, P. R. China
}

\begin{abstract}
The main efforts and applications up to now are focused on the spatial variability analysis within a field. The spatial variability of soil properties within a field was evaluated using geostatistical analysis and the interpolation methods for mapping soil properties were compared in this paper. This experimentation was conducted in a wheat field of the trail farm in Shunyi County, Beijing. The soil properties tested were N, P, and $\mathrm{K}$. The results suggested that the spatial variability of $\mathrm{P}$ were more obvious than $\mathrm{N}$ and $\mathrm{K}$, the random sampling error of $\mathrm{N}$ was bigger than $\mathrm{P}$ and $\mathrm{K}$, and the range of $\mathrm{K}$ was larger than $\mathrm{N}$ and $\mathrm{P}$. The techniques of Kriging and Inverse Distance Weighting (IDW) can significantly improve estimation precision compared with Spline technique. Comparison of Kriging and IDW estimations revealed that Kriging performed better than IDW.
\end{abstract}

Keywords: Spatial variability, Geostatistical analysis, Kriging, IDW

\section{INTRODUCTION}

Most researches on the spatial variability in field are mainly concentrated in precision agriculture for years. However, because of the complexity of crop growing conditions and the difference in crop production within every field, the spatial variability of soil properties that affect especially crop yield should be studied in every field, and the rational sampling interval and sampling density should be also identified. These test data can be finally used to create the spatial variability maps of soil properties with the local 
estimation method (Wollenhaupt et al., 1997; Ping \& Green, 2000). Improvement in estimation quality depends on reliable interpolation techniques that can be used for obtaining soil property values at unsampled locations. Local interpolation techniques commonly used in agricultural applications include IDW, Spline and Kriging (Kravchenko \& Bullock, 1998; Vieira, 1996; Johnson et al., 1998). Description of GIS spatial data structure

\section{MATERIALS AND METHODS}

The experimental field is located at a demo farm in Shunyi County, Beijing. The field surveyed is approximately 11 hectares and the cropping sequences are winter wheat and summer corn. With a DGPS, AgGPS 132, the field was divided into $40 * 40 \mathrm{~m}$ grids and 72 soil samples were collected. The soil properties tested are N, P, and K. All soil samples were collected at depth of $0-20 \mathrm{~cm}$.

The spatial variation in the data was explored using geostatistical analysis. The variogram is a central tool. It describes the structure and the spatial scale of variation by measuring the degree of correlation between the sampling points that are a given distance apart. The experimental variogram is fitted with a variogram model and adequacy of the chosen model is tested using a cross-validation technique. In this study we considered spherical, Gaussian, and exponential models for the experimental variogram fitting. The accuracy of the selected variogram model was measured through the error between the measured data and the estimated values. After an appropriate variogram model was selected, Kriging was used to estimate weights based on the variogram model. Thus the variable values at unsampled locations were obtained.

The factors affecting IDW precision is the number of the closest samples used for estimation. In this study, the number of the closest samples was equal to 12 for all studied data sets. The search radius was chosen so that it was large enough to include the required number of the closest samples. Cross-validation technique was used to compare the results obtained with different number of the closest samples. For Spline method, thin-plate smoothing Spline is constructed based on a tradeoff between goodness of fit and smoothness.

\section{RESULTS AND DISCUSSIONS}

The statistical analysis of the data sets is performanded for $\mathrm{N}, \mathrm{P}$ and $\mathrm{K}$ data. The variance of $\mathrm{P}$ content was more evident than the variance of $\mathrm{N}$ 
content and $\mathrm{K}$ content, with the coefficient of variation equal to $37 \%$ for $\mathrm{P}$. The values of $P$ contents varied with the maximum of $88.6 \mathrm{mg} / \mathrm{kg}$ and the minimum of $16.6 \mathrm{mg} / \mathrm{kg}$. Histograms for $\mathrm{N}, \mathrm{P}$ and $\mathrm{K}$ data were constructed and plotted along with theoretically normal and lognormal probability density functions. P-P probability chart was used to analyze the observed distributions by software SPSS (SPSS Inc., Chicago, USA). The results suggested that $\mathrm{N}, \mathrm{P}$ and $\mathrm{K}$ contents exhibit normal distributions.

The geostatistical analysis of soil properties is accomplished. Experimental variograms for $\mathrm{N}, \mathrm{P}$ and $\mathrm{K}$ data were calculated and fitted with variogram models. The experimental variograms were best fitted with spherical models for $\mathrm{N}$ and $\mathrm{K}$ data sets, and exponential models were used for $\mathrm{P}$ data sets. $\mathrm{C}_{0}$ is the nugget variance, which means the random spatial variability. $\mathrm{C}+\mathrm{C}_{0}$ is the sill, which indicates the amount of the spatial variability of the variable. $\alpha$ is the range and $h$ is the sampling interval. When $h \leq \alpha$, any two sample points have relativity, and the relativity decreases while the value of $h$ increases. When $h>\alpha$, there will be no more relativity between samples. The value of $\alpha$ indicates the degree of the spatial variability of the variable. In other words, $\alpha$ measures the spatial dependence of samples.

The analysis results show that $\mathrm{C}_{0} /\left(\mathrm{C}_{0}+\mathrm{C}\right)$ of $\mathrm{N}$ was 0.769 , which indicates that the random spatial variability of $\mathrm{N}$ is $76.9 \%$ of the total spatial variability. It was the maximum among all the soil parameters. The range of spatial correlation increased from 40.7 to $53.6 \mathrm{~m}$, i.e. if we sample soil for these properties, the sampling interval should be about $40 \mathrm{~m}$. Of course, as time goes by, the range of each soil parameter keeps changing, but it will not change too much.

The interpolation models and Mean Square Error (MSE) are carried out by comparing measured data with estimates of Kriging, Spline and IDW. The most significant difference was observed in MSE values. Kriging and IDW were overall better than Spline. For the Kriging, spherical model and exponential model were better than gauss model. For IDW, the exponent values of 2 was better than the exponent values of 1 and 3 . For the studied data sets, it was the best to create spatial distribution maps using Kriging with spherical model for $\mathrm{N}$ and $\mathrm{K}$, and with exponential model for $\mathrm{P}$.

\section{CONCLUSION}

Experimental variograms showed that the spatial structure of soil properties could be described by spherical, exponential or gaussian models. Variogram model parameters varied markedly according to the soil properties. The extent of spatial variability in this field was given by the range of spatial correlation of the variogram, which varied from $40.7 \mathrm{~m}$ for $\mathrm{P}$, to $53.6 \mathrm{~m}$ for $\mathrm{K}$. Above data were also used to compare performances of 
different interpolation techniques such as Kriging, IDW and Spline. Obtained results indicated that Kriging and IDW could be expected to produce overall better estimations than Spline. For Kriging, furthermore, spherical model was better than exponential model and gauss model for $\mathrm{N}$ and $\mathrm{K}$, and exponential model was better than spherical model and gauss model for P. High values of coefficient of variation could be an indication that Kriging with exponential model would be a better choice. Comparing Kriging with IDW revealed that Kriging with the optimal number of neighboring points, carefully selected variogram model produced more accurate estimations than IDW method for such data sets. In a word, proper geostatistical analysis will provide invaluable information for the spatial distribution of soil properties in agricultural fields.

\section{ACKNOWLEDGEMENTS}

This paper is supported by Ministry of Education-New century talent program NCET-06-0110.

\section{REFERENCES}

Liu Gang, Zhang Man, Wang Maohua. Study on spatial variability of crop yield and soil properties. Proceedings of the 31. International symposium on Agricultural, Opatija, Croatia, 2003, pp. 75-84

Liu Gang, Kuang Jishuang. The study on field soil sampling strategies and interpolation techniques. Information technology of agriculture, ICAST. 2001, pp. 169-178

S.H. Moore, M.C. Wolcott. Spatial Associations between Crop Yield and Soil Characteristics in Corn and Soybean. Proceeding of the 5th International Conference Precision Agriculture, USA, University Minnesota, Oct. 2000, pp. 98-112

John. V. Stafford. Implementing Precision Agriculture in the 21st Century, J. Agric. Engineering Res. 2000 (76), pp. 267-275

Wollenhaupt N.C., Mulla D.J., Gotway Crowford C.A. Soil Sampling and Interpolation Techniques for Mapping Spatial Variability of Soil Properties. The Site-Specific Management for Agricultural Systems. ASA-CSSA-SSSA, 777 S. Segoe Rd., Madison, WI53711, USA, 1997, pp. 19-53

Kravchenko A.N., Bullock D.G. Comparison of Interpolation Methods for Mapping Soil P and K Contents. Proceedings of the 4th International Conference on Precision Agriculture, 19-22 July 1998. St. Paul, MN. pp. 267-280

Jianli Ping, Cary J. Green. Spatial Variability of Yield and Soil Parameters in Two Irrigation Cotton Fields Texas. Proceeding of the 5th International Conference Precision Agriculture, USA, University Minnesota, Oct. 2000, pp. 161-172

Simon Blackmore, Godwin R.J., Taylor J.C. etc. Understanding Variability in Four Fields in the United Kingdom. Proceedings of the 4th International Conference on Precision Agriculture, 19-22 July 1998. St. Paul, MN. pp. 3-18 